\title{
ASYMPTOTIC BEHAVIOR OF GELFAND-NAIMARK DECOMPOSITION
}

\author{
HUAJUN HUANG
}

Abstract. Let $X=L \sigma U$ be the Gelfand-Naimark decomposition of $X \in \mathrm{GL}_{n}(\mathbb{C})$, where $L$ is unit lower triangular, $\sigma$ is a permutation matrix, and $U$ is upper triangular. Call $u(X):=\operatorname{diag} U$ the $u$-component of $X$. We show that in a Zariski dense open subset of the $\omega$-orbit of certain Bruhat decomposition,

$$
\lim _{m \rightarrow \infty}\left|u\left(X^{m}\right)\right|^{1 / m}=\operatorname{diag}\left(\left|\lambda_{\omega(1)}\right|, \cdots,\left|\lambda_{\omega(n)}\right|\right) .
$$

The other situations where $\lim _{m \rightarrow \infty}\left|u\left(X^{m}\right)\right|^{1 / m}$ converge to different limits or diverge are also discussed

Mathematics subject classification (2000): 15A23, 15A42.

Keywords and phrases: Gelfand-Naimark decomposition, Bruhat decomposition, $u$-component, eigenvalues.

\section{REFERENCES}

[1] R. G. Bartle And D. R. Sherbert, Introduction to Real Analysis, Wiley, 1999.

[2] R. Goodman and N. R. Wallach, Representations and Invariants of the Classical Groups, Cambridge University Press, 2000.

[3] R. A. Horn And C. R. Johnson, Topics in Matrix Analysis, Cambridge Univ. Press, 1991.

[4] H. HuAng AND T. Y. TAM, An asymptotic behavior of $Q R$ decomposition, Linear Algebra and Its Applications, 424 (2007) 96-107.

[5] H. HuAng AND T. Y. TAM, On Gelfand-Naimark decomposition of a nonsingular matrix, Linear and Multilinear Algebra (to appear).

[6] H. HuAng AND T. Y. TAM, On the QR iterations of real matrices, Linear Algebra and Its Applications, 408 (2005) 161-176.

[7] H. Huang And T. Y. TAM, Some asymptotic behaviors associated with matrix decomposition, International J. of Information \& Systems Sciences, (2008) 148-159.

[8] E. TyRTyshnikov, Matrix Bruhat decompositions with a remark on the $Q R(G R)$ algorithm, Linear Algebra and Its Applications, 250 (1997) 61-68.

[9] T. Yамамото, Extreme values of the roots of matrices, J. Math. Soc. Japan, 19 (1967) 171-178. 